\title{
Endoscopic Images before the Onset of Cronkhite-Canada Syndrome
}

Kazumasa Kawashima ${ }^{1}$, Takuto Hikichi ${ }^{2}$, Michio Onizawa ${ }^{1}$ and Hiromasa Ohira ${ }^{1}$

Key words: Cronkhite-Canada syndrome, Gastric lesion

(Intern Med Advance Publication)

(DOI: 10.2169/internalmedicine.7369-21)
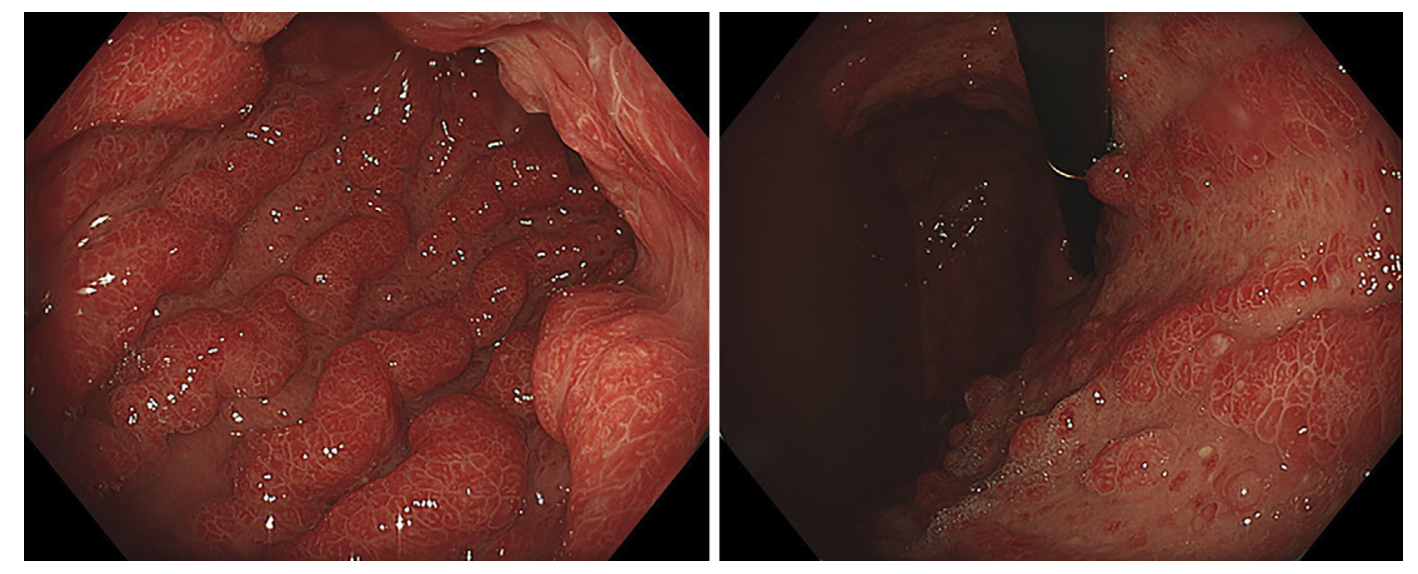

Picture 1.
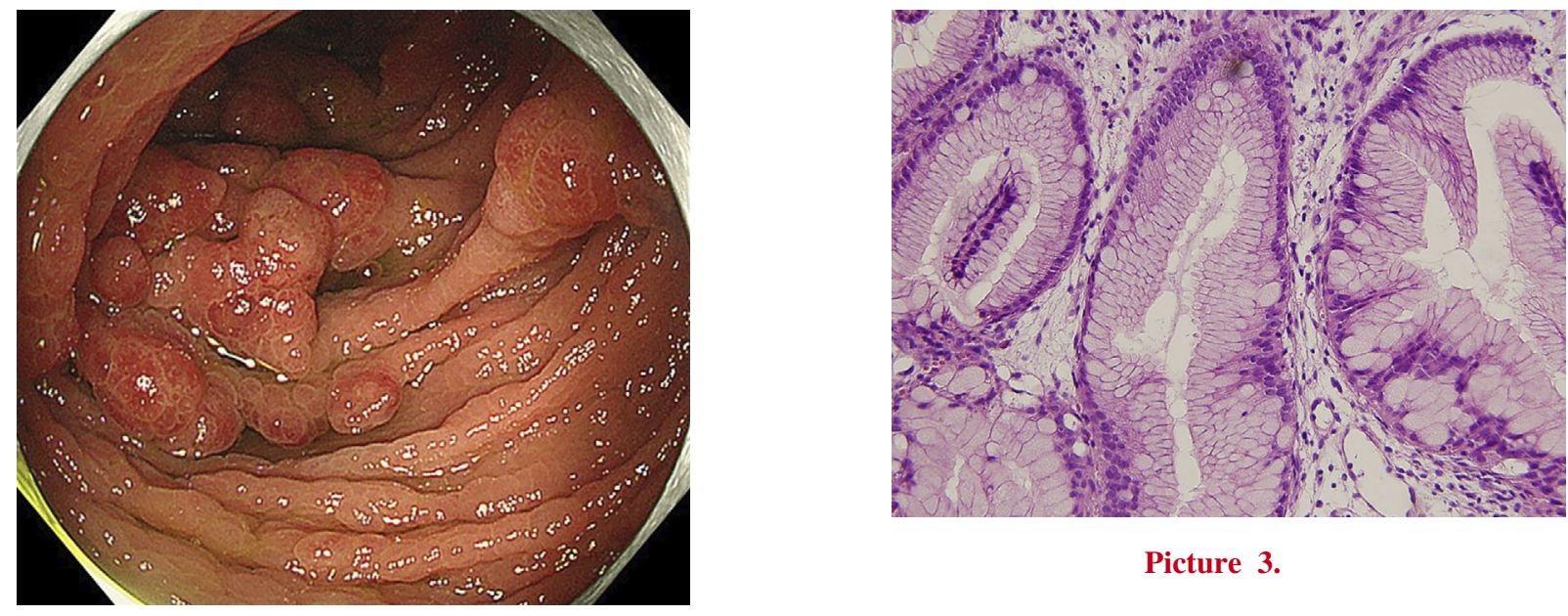

Picture 3.

Picture 2.

A 72-year-old man presented with a 3-month history of diarrhea and weight loss. In addition, he had nail deformi- ties and hypoalbuminemia. Endoscopic imaging showed diffuse, reddish, elevated lesions throughout the stomach (Pic-

\footnotetext{
${ }^{1}$ Department of Gastroenterology, Fukushima Medical University School of Medicine, Japan and ${ }^{2}$ Department of Endoscopy, Fukushima Medical University Hospital, Japan

Received: February 18, 2021; Accepted: April 12, 2021; Advance Publication by J-STAGE: June 19, 2021

Correspondence to Dr. Kazumasa Kawashima, d04120@ fmu.ac.jp
} 

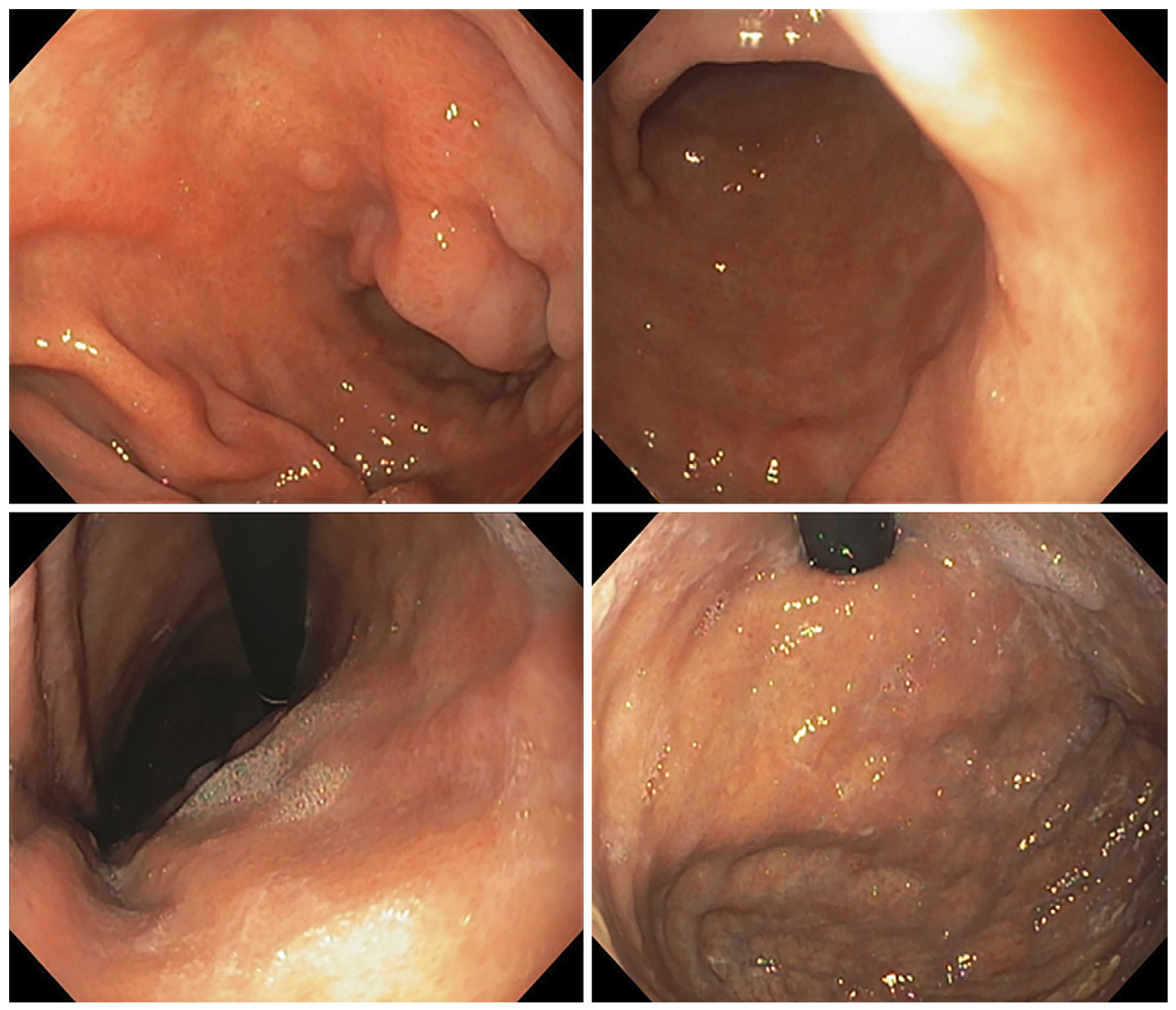

Picture 4.

ture 1) and colon (Picture 2). A histopathological examination of biopsy specimens from the stomach revealed epithelial hyperplasia and edematous stroma with lymphocyte infiltration (Picture 3). Accordingly, he was diagnosed with Cronkhite-Canada syndrome (CCS). One year before the onset of CCS, no hypoalbuminemia or diarrhea had been present; he had no history of eradication for Helicobacter pylori $(H p)$, and serum anti-Hp IgG antibody was negative. Endoscopic images of the stomach showed edematous findings, potentially related to the initial images of CCS (Picture 4). Several reports have described the initial endoscopic findings of the stomach in CCS patients; however, these patients already had symptoms $(1,2)$. In contrast, the endoscopic images of the stomach in this case are considered to reflect findings before the onset of CCS symptoms.
The authors state that they have no Conflict of Interest (COI).

\section{References}

1. Watanabe C, Komoto S, Tomita K, et al. Endoscopic and clinical evaluation of treatment and prognosis of Cronkhite-Canada syndrome: a Japanese nationwide survey. J Gastroenterol 51: 327-336, 2016.

2. Bettington M, Brown IS, Kumarasinghe MP, et al. The challenging diagnosis of Cronkhite-Canada syndrome in the upper gastrointestinal tract: a series of 7 cases with clinical follow-up. Am J Surg Pathol 38: 215-223, 2014.

The Internal Medicine is an Open Access journal distributed under the Creative Commons Attribution-NonCommercial-NoDerivatives 4.0 International License. To view the details of this license, please visit (https://creativecommons.org/licenses/ by-nc-nd/4.0/).

(C) The Japanese Society of Internal Medicine Intern Med Advance Publication 